\title{
Does the length of stay in hospital affect healthcare outcomes of patients without COVID-19 who were admitted during the pandemic? A retrospective monocentric study
}

\author{
David Fluck ${ }^{1}$ - Christopher Henry Fry ${ }^{2} \cdot$ Suzanne Rankin $^{3} \cdot$ Andrea Lewis $^{3}$. Jonathan Robin ${ }^{3} \cdot$ Jacqui Rees $^{4}$. \\ Jo Finch ${ }^{4} \cdot$ Yvonne Jones $^{4} \cdot$ Gareth Jones ${ }^{4}$. Julia Tudose ${ }^{4} \cdot$ Liz Taylor $^{4} \cdot$ Thang Sieu Han $^{5,6}$
}

Received: 1 January 2022 / Accepted: 2 February 2022 / Published online: 24 February 2022

(c) The Author(s) 2022

\begin{abstract}
Uncertainties remain if changes to hospital care during the coronavirus disease (COVID-19) pandemic had an adverse impact on the care-quality of non-COVID-19 patients. We examined the association of hospital length of stay (LOS) with healthcare quality indicators in patients admitted with general medical conditions (non-COVID-19). In this retrospective monocentric study at a National Health Service hospital (Surrey), data were collected from 1st April 2019 to 31st March 2021, including the pandemic from 1st March 2020. Primary admissions, in-hospital mortality, post-discharge readmission and mortality were compared between the pre-pandemic (reference group) and pandemic period, according to LOS categories. There were $10,173(47.7 \% \mathrm{men})$ from the pre-pandemic and $11,019(47.5 \% \mathrm{men})$ from the pandemic period; mean (SD) age 68.3 year (20.0) and 68.3 year (19.6), respectively. During the pandemic, primary admission rates for acute cardiac conditions, pulmonary embolism, cerebrovascular accident and malignancy were higher, whilst admission rates for respiratory diseases and common age-related infections, and in-hospital mortality rates were lower. Amongst 19,721 survivors, sex distribution and underlying health status did not significantly differ between admissions before the pandemic and during wave- 1 and wave-2 of the pandemic. Readmission rates did not differ between pre-pandemic and pandemic groups within the LOS categories of $<7$ and 7-14 days, but were lower for the pandemic group who stayed $>14$ days. For patients who died within seven days of admission, in-hospital mortality rates were lower in patients admitted during the pandemic. Mortality rates within 30 days of discharge did not differ between pre-pandemic and pandemic groups, irrespective of the initial hospital LOS. Despite higher rates of admission for serious conditions during the pandemic, in-hospital mortality was lower. Discharge time was similar to that for patients admitted before the pandemic, except it was earlier during the pandemic for those who stayed $>14$ days, There were no group differences in quality-care outcomes.
\end{abstract}

Keywords Older age $\cdot$ Mortality $\cdot$ Readmission $\cdot$ Length of stay $\cdot$ Coronavirus $\cdot$ Charlson comorbidity index

\begin{tabular}{llll}
\multicolumn{2}{l}{ Abbreviations } & ICD & International classification of diseases \\
CCI & Charlson comorbidity index & LOS & Length of stay \\
CI & Confidence interval & NHS & National Health Service
\end{tabular}

COVID-19 Coronavirus disease-19

Thang Sieu Han

thang.han@rhul.ac.uk

1 Department of Cardiology, Ashford and St Peter's Hospitals NHS Foundation Trust, Guildford Road, Chertsey KT16 0PZ, Surrey, UK

2 School of Physiology, Pharmacology and Neuroscience, University of Bristol, Bristol BS8 1TD, UK

3 Department of Medicine, Ashford and St Peter's Hospitals NHS Foundation Trust, Guildford Road, Chertsey KT16 0PZ, Surrey, UK
4 Department of Quality, Ashford and St Peter's Hospitals NHS Foundation Trust, Guildford Road, Chertsey KT16 0PZ, Surrey, UK

5 Department of Endocrinology, Ashford and St Peter's Hospitals NHS Foundation Trust, Guildford Road, Chertsey KT16 0PZ, Surrey, UK

6 Institute of Cardiovascular Research, Royal Holloway, University of London, Egham TW20 0EX, Surrey, UK 
OR Odds ratio

SD Standard deviation

\section{Introduction}

The coronavirus disease (COVID-19) pandemic had led to an abrupt transformation in healthcare systems [1,2]. There was an urgent need for rapid modification and expansion of hospital ward structures [3, 4], mobilisation of healthcare professionals, and reorganisation of medical and surgical provisions $[5,6]$. Consequently, there was a significant reduction in healthcare service delivery as well as service utilisation [7-11], which particularly affected older adults [12], patients with mental health disorders [13], and individuals of lower socioeconomic status $[14,15]$.

Since the beginning of the COVID-19 pandemic, there has been an unprecedented amount of research and publications devoted to the management of COVID-19 patients. However, comparable research on general medical conditions (non-COVID-19) has diminished, although the latter group comprises the majority (almost 90\%) of all hospital admissions [5]. There has been a suggestion that many older people were generally discharged more rapidly during the pandemic [16]. Despite the huge challenges brought on by the pandemic, the National Health Service (NHS) has continued to maintain the highest possible standards of care for all patients admitted to hospital. However, uncertainties remain if changes adapted to hospital care for COVID-19 could have an adverse impact on quality of care for patients who presented with general medical conditions. We examined the association hospital length of stay (LOS), a measure of time to discharge, with healthcare quality indicators (post-discharge readmission and mortality) both in patients admitted with general medical conditions (non-COVID-19 related) during the COVID-19 pandemic in comparison to patients admitted during the immediately preceding year.

\section{Methods}

\section{Study design, participants and setting}

We analysed prospectively collected data of consecutive unplanned admissions to a single NHS hospital (Ashford and St Peter's NHS Foundation Trust, Surrey, UK), comprising a reference group of patients admitted before the COVID-19 pandemic (1st April 2019 to 29th February 2020), and patients who presented with general medical conditions (without COVID-19) during the pandemic (1st March 2020 to 31st March 2021). Our centre is the largest provider of acute hospital services in Surrey County, serving a catchment area of 450,000 across the north-west of
Surrey. There are 450 hospital beds with a broad range of medical specialties including the following: accident and emergency services, critical care, and emergency medical care which covers the majority of medical disciplines such as cardiology, respiratory medicine, gastroenterology, neurology, endocrinology, geriatrics, oncology and haematology (follow this link for complete list: https://www.ashfordstp eters.nhs.uk/specialties). This centre was appointed as hub for the care of COVID-19 patients.

\section{Selection criteria}

From a total of 22,644 patients, there were 10,173 admitted before and 12,471 during the COVID-19 pandemic. Patients who were admitted with COVID-19 $(n=1452)$ were excluded, leaving 21,192 non-COVID-19 patients admitted before and during the pandemic period eligible for this study (Supplementary Fig. 1). The average rates of admission were 925 month before the pandemic and 959 months during the pandemic (848 month non-COVID-19 and 111 month COVID-19 patients).

\section{Measurements}

Clinical data were recorded including age, sex and comorbidities (coded according to the international classification of diseases, ICD-11) [17]. Charlson comorbidity index (CCI) scores were calculated from comorbidities [18]. Information on care quality including the LOS, frequency of readmissions within 28 days and mortality in hospital and within 30 days of discharge from hospital was documented.

\section{Categorisation of variables}

Age was grouped into bands of $18-39,40-59,60-79$ and $\geq 80$ years and CCI was categorised into three groups with scores of 0,1 and $\geq 2$. Frequencies of early readmissions were categorised either into a single readmission or $\geq 2$ readmissions within 28 days of discharge. Hospital LOS was classified into the following three groups: $<7$, $7-14$ and $>14$ days to indicate early, intermediate and late discharge from hospital.

\section{Statistical analysis}

Chi-square and Fisher's exact tests were used to examine differences between categorical variables including age bands, sex, CCI as well as cause of primary admission and outcomes including in-hospital mortality, readmission and mortality according to LOS categories. Logistic regression was used to assess the risk of readmission and mortality after hospital discharge (dependent variables) in patients admitted during the COVID-19 pandemic compared to those admitted 
before the pandemic (reference group). Data are presented as two models: model 1: unadjusted, and model 2: adjusted for age, sex, $\mathrm{CCI}$ and primary admissions. Odds ratios (OR) are given with $95 \%$ confidence intervals (CI). Analyses were performed using IBM SPSS Statistics, v25.0 (IBM Corp., Armonk, NY).

\section{Results}

\section{Characteristics of pre-pandemic and pandemic groups}

A total of 21,192 non-COVID-19 patients were studied as follows: 10,173 (47.7\% men) from the pre-pandemic and 11,019 (47.5\% men) from the pandemic period; mean (SD) age 68.3 years (20.0) and 68.3 years (19.6), respectively. Compared to pre-pandemic group, the LOS in hospital during the pandemic was shorter by 1.3 days ( $95 \%$ confidence interval: $1.0-1.6, P<0.001$ ), and primary admissions during the pandemic were proportionally higher for acute coronary syndrome and acute myocardial infarct, pulmonary embolism, cerebrovascular accident, and malignancy. By contrast, admission rates for respiratory conditions and common infections such as chronic obstructive pulmonary disease, asthma and pneumonia, pneumonia, urinary tract infection and sepsis were significantly lower. There were no group differences in admissions for congestive heart failure, brain trauma, gastrointestinal conditions including inflammatory bowel disease and gastrointestinal haemorrhage, or diabetes mellitus (Table 1).

There were 1434 in-hospital deaths, and 19,721 patients who survived to discharge, 9401 ( $47.6 \% \mathrm{men})$ from prepandemic and 10,320 (47.3\% men) from COVID-19 pandemic period, with mean (SD) age of 67.2 years (20.2) and 67.4 years (19.7), respectively. Compared to patients admitted before the pandemic, those admitted during the pandemic had similar sex distribution or CCI scores, but proportionally more for those aged 40-79 years, whilst the rates of readmission within 28 days $(11.9 \%$ vs $10.1 \%$, $P<0.001)$ and mortality within 30 days of hospital discharge (4.6\% vs $4.1 \%, P=0.025)$ were lower. There were higher proportions of patients with $\operatorname{LOS}<7$ days $(75.7 \%$ versus $77.3 \%), 7-14$ days (10.9\% vs $12.8 \%$ ), and conversely there was a lower proportion with LOS $>14$ days ( $13.3 \%$ vs $9.9 \%)$ (Table 1).

\section{Outcomes differences between pre-pandemic and pandemic groups according to LOS in hospital}

In-hospital mortality rate during the pandemic $(6.0 \%)$ was significantly $\left(\chi^{2}=20.4, P<0.001\right)$ lower than that before the pandemic (7.6\%). In-hospital mortality rates rose incrementally with longer LOS in hospital in both study groups (pre-pandemic: $\chi^{2}=394.9, P<0.001$; during pandemic: $\left.\chi^{2}=363.5, P<0.001\right)$. Generally, in-hospital mortality rates were lower for any given LOS in hospital (Fig. 1A). The age of patients who died in hospital before the pandemic (mean $=81.9$ years, $\mathrm{SD}=11.8)$ did not differ $(P=0.186)$ from that of patients who died during the pandemic $($ mean $=81.1$ years, $\mathrm{SD}=12.4)$.

Amongst patients with LOS $<7$ days in hospital, the proportions of early readmission within the pre-pandemic group were $7 \%$, rising to 22.8 and $31.1 \%$ amongst those who stayed in hospital 7-14, and $>14$ days, respectively $\left(\chi^{2}=721.6, P<0.001\right)$. The corresponding figures for those admitted during the pandemic group were 6.6, 20.7 and $23.4 \%\left(\chi^{2}=468.6, P<0.001\right)$. There were no group differences in the rates of readmission within LOS categories of $<7$ days and 7-14 days. By contrast, with the LOS category of $>14$ days, and compared to the reference group, there was a lower proportion of patients admitted during the pandemic who were readmitted at least once within 28 days of discharge ( $31.1 \%$ vs $23.4 \%, P<0.001)$ (Fig. 1B).

Similarly, the rates of mortality within 30 days of discharge were lowest $(2.1 \%)$ amongst those admitted before the pandemic (reference) and with the shortest LOS ( $<7$ days). This increased to 10.7 and $14 \%$ for those who stayed in hospital 7-14, and $>14$ days, respectively $\left(\chi^{2}=439.2, P<0.001\right)$. The corresponding figures for those who were admitted during the pandemic were 1.9, 11.2 and $12.0 \%\left(\chi^{2}=438.7, P<0.001\right)$. There were no significant differences in the rates of mortality within 30 days of hospital discharge between pre-pandemic and pandemic groups who stayed in hospital $<7$ days $(2.1 \%$ vs $1.9 \%, P=0.147)$, $7-14$ days $(10.7 \%$ vs $11.2 \%, P=0.376)$, or $>14$ days $(14.0 \%$ vs $12.0 \%, P=0.085)$ (Fig. 1C).

Within each category of LOS, there was an increasing trend with greater age for readmission within 28 days of discharge (Fig. 2A, B) and of mortality within 30 days of discharge (Fig. 3A, B). This was duplicated by both the pre-pandemic and the pandemic groups, except for a surge in readmissions amongst the youngest group within the 7-14 days LOS category. In general, the rates of readmission and mortality were lower amongst patients who were admitted during the pandemic within each age category (Figs. 2, 3).

The distributions of age (Fig. 4A) and CCI (Fig. 4B) did not differ substantially between patients admitted before the pandemic and those admitted during either wave- 1 or wave- 2 of the pandemic.

Logistic regression analysis with adjustment for age, sex, CCI and primary admissions showed that compared with patients who were admitted before the COVID19 pandemic, patients who were admitted during the pandemic had similar risk of readmission and mortality 
Table 1 Characteristics of 21,192 patients admitted before and of those admitted during the COVID-19 pandemic

\begin{tabular}{|c|c|c|c|}
\hline & \multicolumn{2}{|c|}{ Proportion of patients (\%) } & \multirow{2}{*}{$\begin{array}{l}\text { Group dif- } \\
\text { ferences ( } P \\
\text { values) }\end{array}$} \\
\hline & $\begin{array}{l}\text { Before pandemic } \\
(n=10,173)\end{array}$ & $\begin{array}{l}\text { During pandemic } \\
(n=11,019)\end{array}$ & \\
\hline \multicolumn{4}{|l|}{ Age on admission (year) } \\
\hline $18-39$ & 11.8 & 10.8 & \multirow[t]{4}{*}{0.008} \\
\hline $40-59$ & 19.6 & 20.8 & \\
\hline $60-79$ & 32.9 & 33.7 & \\
\hline$\geq 80$ & 35.8 & 34.8 & \\
\hline \multicolumn{4}{|l|}{ Sex } \\
\hline Men & 47.7 & 47.5 & \multirow[t]{2}{*}{0.358} \\
\hline Women & 52.3 & 52.5 & \\
\hline \multicolumn{4}{|l|}{ Primary admissions } \\
\hline Acute coronary syndrome & 0.6 & 0.8 & 0.018 \\
\hline Acute myocardial infarct & 3.7 & 4.2 & 0.021 \\
\hline Pulmonary embolism & 1.1 & 1.4 & 0.022 \\
\hline Cerebrovascular accident & 4.6 & 5.2 & 0.023 \\
\hline Malignancy & 2.3 & 2.8 & 0.015 \\
\hline Chronic obstructive pulmonary disease & 2.1 & 1.7 & 0.019 \\
\hline Asthma & 1.2 & 0.6 & $<0.001$ \\
\hline Pneumonia & 10.0 & 5.1 & $<0.001$ \\
\hline Urinary tract infection & 4.9 & 4.3 & 0.015 \\
\hline Sepsis & 1.8 & 1.3 & 0.001 \\
\hline Congestive heart failure & 1.8 & 2.1 & 0.070 \\
\hline Brain trauma & 1.0 & 0.8 & 0.161 \\
\hline Inflammatory bowel disease & 0.8 & 0.7 & 0.398 \\
\hline Gastrointestinal haemorrhage & 1.1 & 1.0 & 0.372 \\
\hline Diabetes mellitus & 1.5 & 1.4 & 0.358 \\
\hline \multicolumn{4}{|l|}{ Charlson comorbidity index scores } \\
\hline 0 & 86.3 & 86.0 & \multirow[t]{3}{*}{0.077} \\
\hline 1 & 10.2 & 9.9 & \\
\hline$\geq 2$ & 3.5 & 4.1 & \\
\hline \multicolumn{4}{|l|}{ Length of stay in hospital } \\
\hline$<7$ days & 73.3 & 75.3 & \multirow[t]{3}{*}{$<0.001$} \\
\hline $7-14$ days & 11.7 & 13.6 & \\
\hline$>14$ days & 15.0 & 111.1 & \\
\hline Mortality in hospital & 7.6 & 6.0 & $<0.001$ \\
\hline Mortality within 30 days of discharge & 4.6 & 4.1 & 0.025 \\
\hline \multicolumn{4}{|l|}{ Readmissions within 28 days of discharge } \\
\hline No readmission & 88.1 & 89.9 & \multirow[t]{3}{*}{$<0.001$} \\
\hline Single readmission & 9.1 & 7.7 & \\
\hline$\geq 2$ readmissions & 2.8 & 2.4 & \\
\hline
\end{tabular}

after a discharge from hospital, irrespective of the LOS. The only exception was of a lower risk of in-hospital mortality for those who died in hospital within 7 days of admission and for readmission within 28 days of discharge for those who stayed in hospital $>14$ days (Table 2).

\section{Discussion}

\section{Summary}

Compared to pre-pandemic period, for patients with nonCOVID related conditions during the pandemic period, the 
(A)

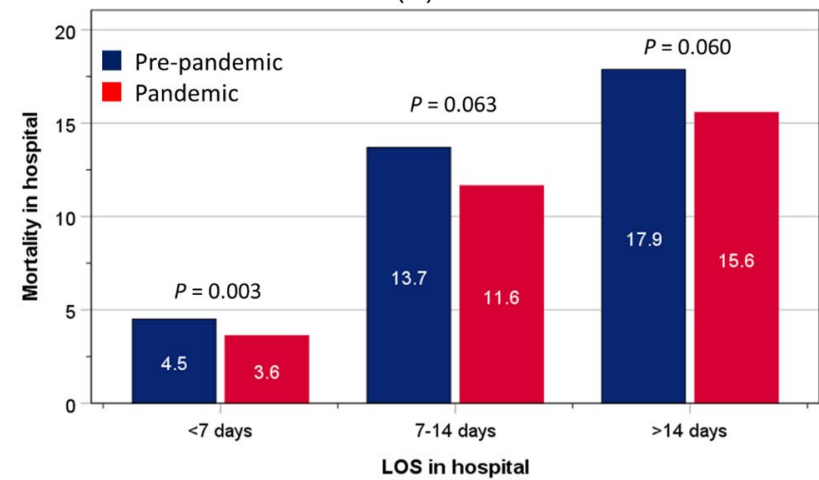

(B)

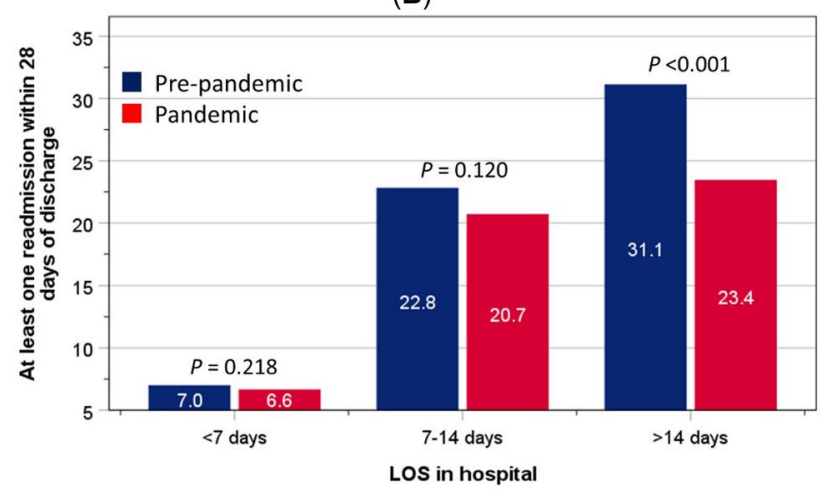

(C)

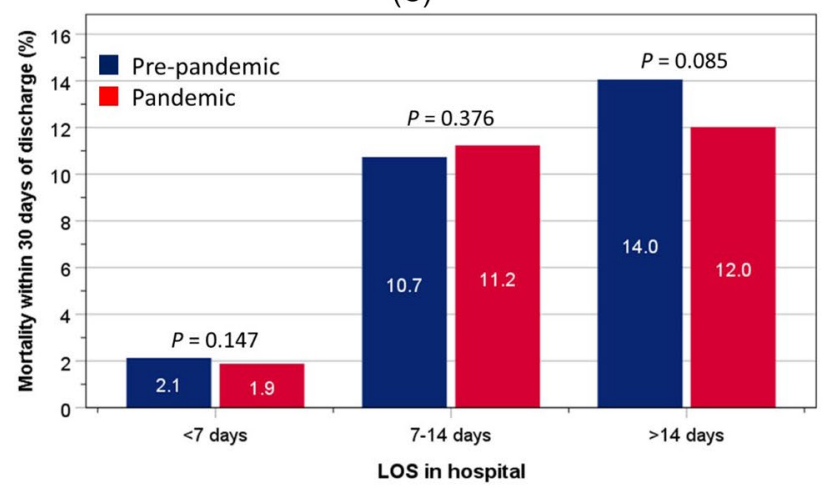

Fig. 1. In-hospital mortality rates (A), readmission within 28 days (B), and mortality within 30 days (C) of hospital discharge, according to LOS amongst patients admitted before the pandemic and those admitted during the pandemic

admission rates for serious conditions such as acute cardiac conditions, pulmonary embolism, cerebrovascular accident and malignancy were higher, whilst those for respiratory diseases and common age-related infections and in-hospital mortality were lower. There was no evidence for a risk of early readmission or short-term mortality amongst those who were discharged early (hospital LOS $<7$ days): this was irrespective of age, sex and CCI. Our findings, therefore, indicate that standards of care were maintained for non-COVID-19 patients admitted to our hospital during the pandemic, and continued to fulfil the standards set by the
(A)

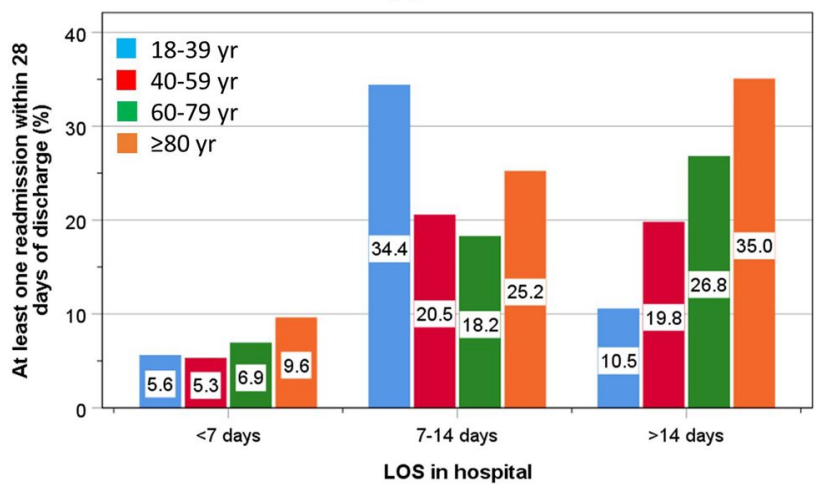

(B)

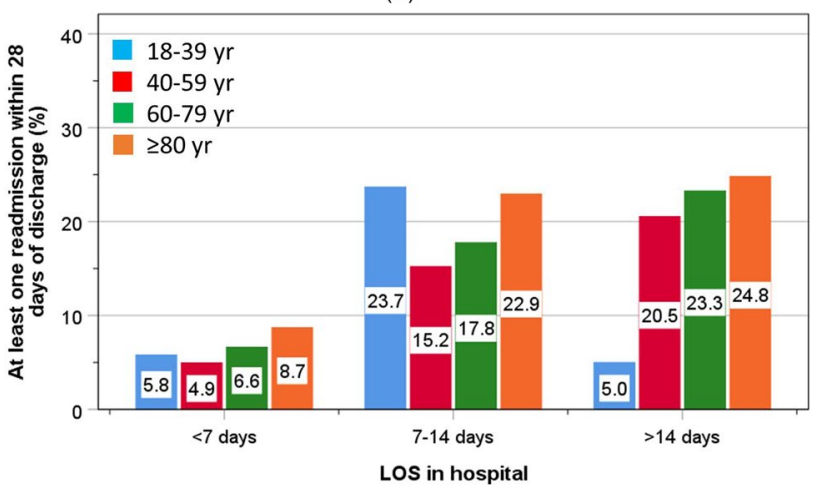

Fig. 2. Distribution of readmissions at least once within 28 days of discharge amongst patients admitted before (A) and during the pandemic (B) according to age

Getting It Right First Time programme. As far as we are aware, no such research findings have been reported in current literature.

\section{LOS and care-quality outcomes}

The findings of a higher proportion of patients with early discharge (LOS $<7$ days) and a lower proportion with late discharge (LOS $>14$ days) during the pandemic, whilst care-quality outcomes (readmission and mortality) were not compromised, suggest that efficiency of discharge planning may have improved, as well as greater efforts were made in the management of patients. In addition, we followed the national guidelines with the implementation of surge rota [20], redeployment of staff [21] and deferral of annual leave [22]. Similar to other centres, there was a restructure and expansion of hospital wards such as critical care units [23], and a shift from face-to-face outpatient clinics to telephone clinics [5]. These measures were likely to have a positive impact on overall ability to maintain non-COVID cover. There was also a reduction of non-emergency surgical activity, but we did not need to divert any patients to other hospitals. 
(A)

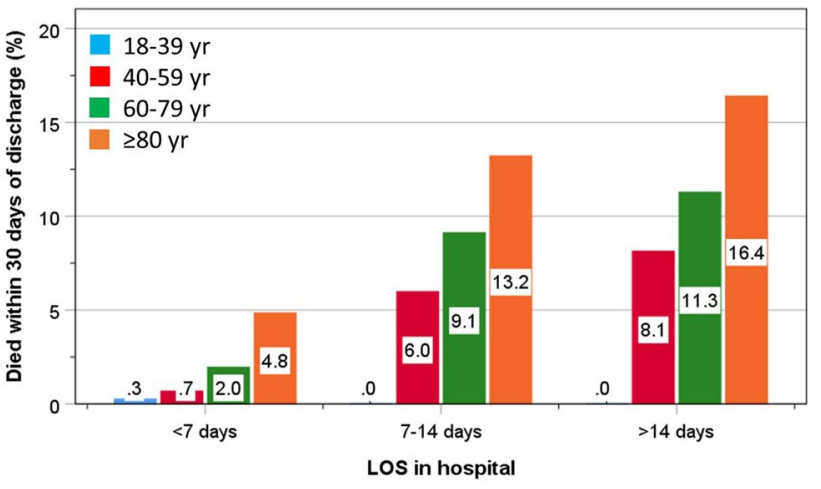

(B)

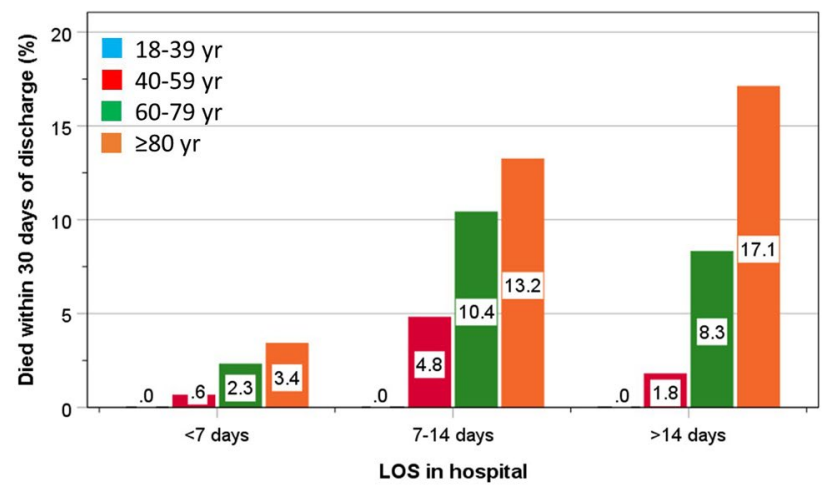

Fig. 3. Distribution of mortality within 30 days of discharge amongst patients admitted before (A) and during the pandemic (B) according to age

In line with national guidelines, there were a number of initiatives carried out at our hospital during the pandemic. These included improvement in hospital discharge and community support which was made possible by a national discharge fund provided by the government from 19th March 2020 until 31st March 2022. This fund covered partially the cost of recovery and support services, rehabilitation and reablement care after hospital discharge, with an intention to assist more people to return to their home [19]. The improved community care after the first COVID-19 pandemic played a pivotal role in reducing hospital readmissions. This includes implementation of the Enhanced Health in Care Homes service to support staff and residents during the pandemic [24]. Admissions and readmissions for many ambulatory care-sensitive and urgent care-sensitive conditions such as chronic obstructive pulmonary disease, asthma and diabetes could be avoided with timely and effective community care. A recent report has indicated that emergency admissions were reduced for ambulatory care-sensitive conditions by $24 \%$ and urgent care-sensitive conditions by $17 \%$ during the pandemic compared to the previous year [25]. The observation in our study of lower rates of admission for
(A)

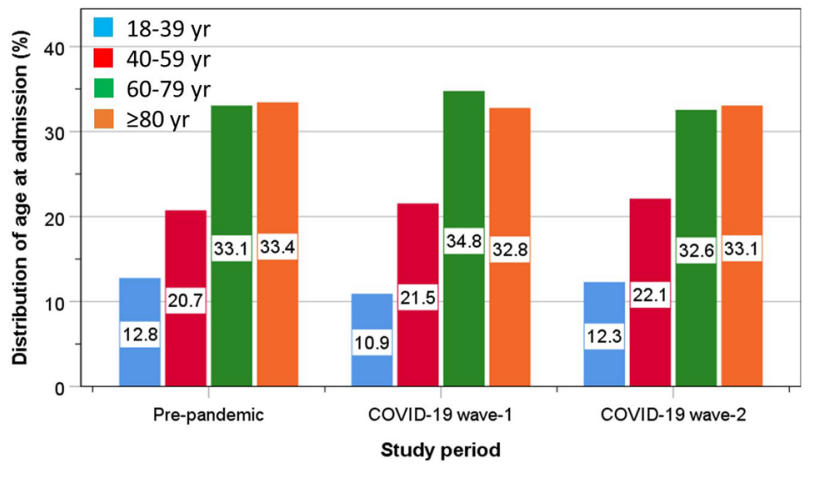

(B)

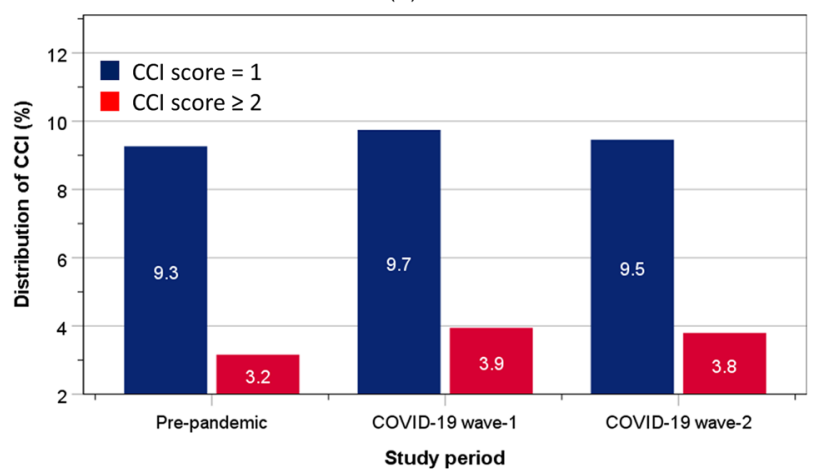

Fig. 4. Distribution of age (A) and Charlson comorbidity index (B) at admission before, during wave-1 and wave-2 COVID-19 pandemic

respiratory diseases (chronic obstructive pulmonary disease and asthma) and common infections associated with older age (pneumonia, urinary tract infection and sepsis), and no change in congestive heart failure and diabetes, during the pandemic is consistent with the findings in the report above. On the other hand, admission rates were higher during the pandemic for serious conditions which cannot be managed in the community including cardiac conditions (acute coronary syndromes and acute myocardial infarction), pulmonary embolism, cerebrovascular accidents and malignancies. The changes in cause of admission during the pandemic were accompanied by a reduction of in-hospital mortality, indicating the overall quality of care was maintained for nonCOVID patients, despite higher proportions of patients who were admitted with serious conditions.

Furthermore, there was an increase in infection control globally, including hygiene and personal protective equipment, that resulted in a very large decrease of nosocomial infections, such as Clostridium difficile infections and improved antibiotic treatments [26, 27]. Consequently, there was a reduction of LOS in the most vulnerable groups of patients such as oncology patients [27].

A number of other changes have also been observed that could have an impact on admission and readmission to 
Table 2 Logistic regression to assess the risk of in-hospital mortality, post-discharge readmission and mortality amongst patients admitted during the pandemic compare to those admitted before the pandemic (reference group)

\begin{tabular}{|c|c|c|c|c|c|c|}
\hline \multirow[t]{3}{*}{ In-hospital mortality } & \multicolumn{6}{|c|}{$\begin{array}{l}\text { Risk from admission during COVID-19 pandemic compared to admission } \\
\text { before the pandemic (reference group) }\end{array}$} \\
\hline & \multicolumn{3}{|c|}{ Unadjusted } & \multicolumn{3}{|c|}{$\begin{array}{l}\text { Adjusted for age, sex, CCI, and } \\
\text { primary admissions }^{\mathrm{a}}\end{array}$} \\
\hline & OR & $95 \% \mathrm{CI}$ & $P$ & OR & $95 \% \mathrm{CI}$ & $P$ \\
\hline LOS $<7$ days & 0.79 & $0.68-0.93$ & 0.005 & 0.80 & $0.67-0.95$ & 0.010 \\
\hline $\mathrm{LOS}=7-14$ days & 0.83 & $0.66-1.04$ & 0.112 & 0.88 & $0.69-1.12$ & 0.288 \\
\hline LOS $>14$ days & 0.85 & $0.69-1.04$ & 0.109 & 0.92 & $0.75-1.14$ & 0.462 \\
\hline $\begin{array}{l}\text { Readmitted within } \\
28 \text { days of discharge }\end{array}$ & OR & $95 \% \mathrm{CI}$ & $P$ & OR & $95 \% \mathrm{CI}$ & $P$ \\
\hline LOS $<7$ days & 0.95 & $0.84-1.08$ & 0.417 & 0.95 & $0.84-1.08$ & 0.466 \\
\hline $\mathrm{LOS}=7-14$ days & 0.88 & $0.73-1.08$ & 0.220 & 0.91 & $0.74-1.11$ & 0.329 \\
\hline LOS $>14$ days & 0.68 & $0.56-0.82$ & $<0.001$ & 0.71 & $0.58-0.86$ & $<0.001$ \\
\hline \multicolumn{7}{|c|}{ Mortality within 30 days of discharge } \\
\hline LOS $<7$ days & 0.88 & $0.70-1.11$ & 0.269 & 0.87 & $0.69-1.11$ & 0.271 \\
\hline $\operatorname{LOS}=7-14$ days & 1.05 & $0.81-1.37$ & 0.700 & 1.05 & $0.80-1.38$ & 0.718 \\
\hline LOS $>14$ days & 0.84 & $0.65-1.07$ & 0.153 & 0.91 & $0.71-1.10$ & 0.489 \\
\hline
\end{tabular}

CCI, Charlson comorbidity index

a primary admissions including 15 conditions presented in Table 1 hospital in many parts of the world. There was a very large reduction [28, 29], or even abolition [30] of influenza admissions. This is likely to result from better hygiene and social distancing and behavioural changes of individuals from fear of contracting COVID-19 infection in hospital [31]. Furthermore, in the UK and other affluent countries [32], family support may have been more readily available since there were more people on furlough schemes [33], which may have helped to allow older patients to be discharged from hospital earlier.

\section{Patient characteristics}

The similarity in distributions of age, sex and underlying health status (CCI) in patients admitted before the pandemic and those admitted during the pandemic indicates that self-selection for hospital admission was not apparent. This suggests that if patients were acutely unwell, irrespective of their age and underlying health status, they were equally likely to be admitted to hospital during the pandemic as those before the pandemic. These findings were confirmed by multivariable logistic regression with adjustments for age, sex and CCI, showing no evidence for an increase in readmission or mortality amongst patients admitted during the pandemic compared to those admitted before the pandemic (reference group), within early, intermediate or late discharge group. These findings were corroborated by evidence that the numbers of patients admitted with general medical conditions was reduced with the surge of COVID-19 admissions with each pandemic wave
[5]. However, there was no evidence for a decrease in the proportions of older adults or those with poorer health status (CCI) during either wave-1 or wave- 2 of the COVID19 pandemic. Overall, the present study found that early discharge before or during the pandemic was associated with better outcomes, which are consistent with previous findings [34].

There were two distinct waves of the COVID-19 pandemic. Similar to national data, COVID-19 admissions to our hospital surged rapidly in wave-1. By contrast, COVID-19 admissions in wave- 2 were more gradual, but the total number of admissions were much higher. We have demonstrated that non-COVID admissions mirrored closely the peaks and troughs of COVID-19 admissions [5].

In addition to higher proportions of patients admitted with serious conditions during the pandemic, in-hospital mortality rates were lower overall with any given hospital LOS (higher burden of comorbidities and frailty), whilst the age of those who died was virtually identical to those admitted before the pandemic. Therefore, the relationship between LOS and post-discharge outcomes were probably not affected by conditions from primary admission or inhospital mortality, i.e. bias from healthier or survivors is unlikely.

\section{Strengths and limitations}

The strengths of this study lies in its large numbers of patients who were consecutively admitted to the same 
centre, and the use of a control group of patients who admitted in the year immediately before the pandemic. The study covered a wide range of age and underlying health status assessed by standardised indices. There is, however, a lack of long-term outcome data, which are not yet available. Caution should be taken if extrapolating our findings to other centres as management of patients during the COVID-19 pandemic may differ between these centres, particularly in other countries where health services are not centrally funded by the government.

In conclusion, despite the higher rates of admission for serious conditions during the pandemic, in-hospital mortality was lower, with discharge time being similar to that of patients admitted before the pandemic, except earlier for those who stayed $>14$ days during the pandemic, whilst there were no group differences in quality care outcomes.

Supplementary Information The online version contains supplementary material available at https://doi.org/10.1007/s11739-022-02945-7.

Acknowledgements The authors wish to thank patients and all those who were involved in the surveys.

Author contributions TSH: reviewed the topic related literature and performed the study concept and analysis design. DF, SR, JR, AL, SR, JR, JF, YJ, GJ, JT, and ET: performed the study coordination and management of patients. TSH: wrote the first draft, analysed, interpreted the data and revised the manuscript. CHF and DF: edited the manuscript. All authors checked, interpreted results and approved the final version.

\section{Declarations}

Conflict of interest The authors declare that they have no conflicts of interest.

Ethical approval This study does not require NHS Research Ethics Committee approval since it involves secondary analysis of anonymised data. This study was conducted in accordance with the 1964 Helsinki declaration and its later amendments or comparable ethical standards. Statement of human and animal rights: This article does not contain any studies with animals performed by any of the authors.

Informed Consent Not applicable.

Open Access This article is licensed under a Creative Commons Attribution 4.0 International License, which permits use, sharing, adaptation, distribution and reproduction in any medium or format, as long as you give appropriate credit to the original author(s) and the source, provide a link to the Creative Commons licence, and indicate if changes were made. The images or other third party material in this article are included in the article's Creative Commons licence, unless indicated otherwise in a credit line to the material. If material is not included in the article's Creative Commons licence and your intended use is not permitted by statutory regulation or exceeds the permitted use, you will need to obtain permission directly from the copyright holder. To view a copy of this licence, visit http://creativecommons.org/licenses/by/4.0/.

\section{References}

1. Archer S, Calanzani N, Honey S, Johnson M, Neal R, Scott SE, Walter FM (2021) Impact of the COVID-19 pandemic on cancer assessment in primary care: a qualitative study of GP views. BJGP Open 5(4). https://doi.org/10.3399/BJGPO.2021.0056

2. Al-Tawfiq JA, Al-Yami SS, Rigamonti D (2020) Changes in healthcare managing COVID and non-COVID-19 patients during the pandemic: striking the balance. Diagn Microbiol Infect Dis 98(4): 115147

3. Weissman GE, Crane-Droesch A, Chivers C, Luong T, Hanish A, Levy MZ, Lubken J, Becker M, Draugelis ME, Anesi GL, Brennan PJ (2020) Locally informed simulation to predict hospital capacity needs during the COVID-19 pandemic. Ann Intern Med 173(1):21-28

4. Chen LK, Yuan RP, Ji XJ, Lu XY, Xiao J, Tao JB, Kang X, Li X, He ZH, Quan S, Jiang LZ (2021) Modular composite building in urgent emergency engineering projects: a case study of accelerated design and construction of wuhan thunder god mountain/ leishenshan hospital to COVID-19 pandemic. Autom In Constr 124:103555

5. Fluck D, Rankin S, Lewis A, Robin J, Rees J, Finch J, Jones Y, Jones G, Kelly K, Murray P, Wood M (2021) Comparison of characteristics and outcomes of patients admitted to hospital with COVID-19 during wave 1 and wave 2 of the current pandemic. Intern Emerg Med. https://doi.org/10.1007/s11739-02102842-5 ([Epub ahead of print])

6. Catania G, Zanini M, Hayter M, Timmins F, Dasso N, Ottonello G, Aleo G, Sasso L, Bagnasco A (2021) Lessons from Italian front-line nurses' experiences during the COVID-19 pandemic: a qualitative descriptive study. J Nurs Manag 29(3):404-411

7. Zhang YN, Chen Y, Wang Y, Li F, Pender M, Wang N, Yan F, Ying XH, Tang SL, Fu CW (2020) Reduction in healthcare services during the COVID-19 pandemic in China. BMJ Glob Health 5(11):e003421

8. Moynihan R, Sanders S, Michaleff ZA, Scott AM, Clark J, To EJ, Jones M, Kitchener E, Fox M, Johansson M, Lang E (2021) Impact of COVID-19 pandemic on utilisation of healthcare services: a systematic review. BMJ Open 11(3):e045343

9. McLean RC, Young J, Musbahi A, Lee JX, Hidayat H, Abdalla N, Chowdhury S, Baker EA, Etherson KJ (2020) A single-centre observational cohort study to evaluate volume and severity of emergency general surgery admissions during the COVID-19 pandemic: is there a "lockdown" effect? Int J Surg 83:259-266

10. Hampton M, Clark M, Baxter I, Stevens R, Flatt E, Murray J, Wembridge K (2020) The effects of a UK lockdown on orthopaedic trauma admissions and surgical cases: a multicentre comparative study. Bone JT Open 1(5):137-143

11. Beghi M, Brandolini R, Casolaro I, Beghi E, Cornaggia CM, Fraticelli C, De Paoli G, Ravani C, Castelpietra G, Ferrari S (2021) Effects of lockdown on emergency room admissions for psychiatric evaluation: an observational study from the AUSL Romagna, Italy. Int J Psychiatry Clin Pract 25(2):135-139

12. Rout N (2020) Risks to the elderly during the coronavirus (COVID-19) pandemic 2019-2020. J Geriatr Care Res 7(1):27-28

13. Egede LE, Ruggiero KJ, Frueh BC (2020) Ensuring mental health access for vulnerable populations in COVID era. J Psychiatr Res 129:147

14. Propper C, Stoye G, Zaranko B (2020) The wider impacts of the coronavirus pandemic on the NHS. Fisc Stud 41(2):345-356

15. Birkmeyer JD, Barnato A, Birkmeyer N, Bessler R, Skinner J (2020) The Impact Of The COVID-19 pandemic on hospital admissions in the United States: study examines trends in US 
hospital admissions during the COVID-19 pandemic. Health Aff 39(11):2010-2017

16. De Biase S, Cook L, Skelton DA, Witham M, Ten Hove R (2020) The COVID-19 rehabilitation pandemic. Age Ageing 49(5):696-700

17. Charlson ME, Pompei P, Ales KL, MacKenzie CR (1987) A new method of classifying prognostic comorbidity in longitudinal studies: development and validation. J Chronic Dis 40(5):373-383

18. World Health Organization. (2021) www.who.int/standards/class ifications/classification-of-diseases/emergency-use-icd-codes-forcovid-19-disease-outbreak Accessed 5 Nov 2021

19. Department of Health. Hospital discharge service guidance (2021) https://www.gov.uk/government/collections/hospital-dischargeservice-guidance Accessed 5 Nov 2021

20. NHS England. (2021) Clinical guide for the management of surge during the coronavirus pandemic: rapid learning. Publications approval reference: 001559 https://www.england.nhs.uk/coronavirus/wp- content/uploads/sites/52/2020/03/C0167-specialty-guidesurge-based-on-current-hospital-experience-v2.pdf Accessed 5 Nov 2021

21. NHS England. (2021) COVID-19: Deploying our people safely. Publications approval reference: 001559. https://www.england. nhs.uk/coronavirus/wp-content/uploads/sites/52/2020/05/C0449covid-19-deploying-our-people-safely-v1.2.pdf Accessed 5 Nov 2021

22. NHS Employers. (2021) Annual leave during COVID-19. Guidance on managing annual leave for your staff during COVID19. https://www.nhsemployers.org/articles/annual-leave-duringcovid-19 Accessed 5 Nov 2021

23. King's Fund. (2021) Critical care services in the English NHS: Covid-19 Hospital care. https://www.kingsfund.org.uk/publicatio ns/critical-care-services-nhs Accessed 5 Nov 2021

24. Hayter A.(2022) The impact of COVID-19 on older people: lessons learned for ageing well. NHS England and NHS improvement. https://www.local.gov.uk/sites/default/files/documents/Dr\% 20Adrian\%20Hayter\%2C\%20GP\%20and\%20National $\% 20 \mathrm{Cli}$ nical\%20Director\%2C\%20NHS\%20England.pdf. Accessed 21 Jan 2022

25. Nuffield Trust. (2022) Potentially preventable emergency admissions. https://www.nuffieldtrust.org.uk/resource/potentially-preve ntable-emergency-hospital-admissions.Accessed 21 Jan 2022
26. Ponce-Alonso M, De La Fuente JS, Rincón-Carlavilla A, MorenoNunez P, Martínez-García L, Escudero-Sánchez R, Pintor R, García-Fernández S, Cobo J (2021) Impact of the coronavirus disease 2019 (COVID-19) pandemic on nosocomial clostridioides difficile infection. Infect Control Hosp Epidemiol 42(4):406-410

27. Irelli EC, Morano A, Di Bonaventura C (2021) Reduction in nosocomial infections during the COVID-19 era: a lesson to be learned. Updat Surg 73(2):785-786

28. Zhang N, Jia W, Lei H, Wang P, Zhao P, Guo Y, Dung CH, Bu Z, Xue P, Xie J, Zhang Y (2021) Effects of human behavior changes during the coronavirus disease 2019 (COVID-19) pandemic on influenza spread in Hong Kong. Clin Infect Dis 73(5):e1142-e1150

29. Olsen SJ, Azziz-Baumgartner E, Budd AP, Brammer L, Sullivan S, Pineda RF, Cohen C (2020) Fry AM (2020) decreased influenza activity during the COVID-19 pandemic-United States, Australia, Chile, and South Africa. Am J Transplant 20(12):3681-3685

30. Koutsakos M, Wheatley AK, Laurie K, Kent SJ, Rockman S (2021) Influenza lineage extinction during the COVID-19 pandemic? Nature Rev Microbiol 19:741-742

31. Khan N, Jones D, Grice A, Alderson S, Bradley S, Carder P, Drinkwater J, Edwards H, Essang B, Richards S, Neal R (2020) A brave new world: the new normal for general practice after the COVID-19 pandemic. BJGP Open. 4(3). https://doi.org/10.3399/ bjgpopen20X101103

32. World Economic Forum. Coronavirus: What does 'furlough' mean and how will it affect workers worldwide? https://www.weforum. org/agenda/2020/04/covid19-furlough-employers-workers-suppo rt-global/. Accessed 5 Nov 2021

33. Savla J, Roberto KA, Blieszner R, McCann BR, Hoyt E, Knight AL (2021) Dementia caregiving during the "stay-at-home" phase of COVID-19 pandemic. J Gerontol: Series B 76(4):e241-e245

34. Han TS, Murray P, Robin J, Wilkinson P, Fluck D, Fry CH (2021) Evaluation of the association of length of stay in hospital and outcomes. Int J Qual Health Care. https://doi.org/10.1093/intqhe/ mzab160 ([Epub ahead of print])

Publisher's Note Springer Nature remains neutral with regard to jurisdictional claims in published maps and institutional affiliations. 